\title{
A Study of the Deficit of the Third Party Liability Compulsory Insurance of Motor Vehicle
}

\author{
Lili Bao ${ }^{1} \&$ Zhengyu $\mathrm{Gu}^{2}$ \\ ${ }^{1}$ Shanghai University of Engineering Science, Shanghai, China \\ ${ }^{2}$ Nanjing University, Nanjing, China \\ Correspondence: Lili Bao, Shanghai University of Engineering Science, Shanghai, China. E-mail: \\ baolili.2009@163.com
}

Received: January 21, 2014

Accepted: February 19, 2014

Online Published: February 20, 2014

doi:10.5430/afr.v3n1p116

URL: http://dx.doi.org/10.5430/afr.v3n1p116

\begin{abstract}
With the rapid development of the popularization of motor vehicles and legal system construction, our daily lives become more convenient. But traffic accidents also have brought pain and heavy economic burden to the public. As the first compulsory insurance in China, the third party liability insurance aims at protect the injured in traffic accident sufficiently. In the recent years, however, the loss of the third party liability compulsory insurance of motor vehicle has aroused the concern of the whole society. Combining with our actual situation, this paper studies this insurance system in order to help to find out the deep causes of losses. Making a profit instead of suffering a loss has an important impact on the health of the insurance companies and the financial industry. Compared to the commercial insurance, the third party liability insurance of motor vehicle needs more improvement. According to the existing data and the foreign insurance operation experience, the paper analyzes the third party liability compulsory insurance of motor vehicle practicality through the comparative analysis. There are three parts to the causal analysis of the operating loss: insurance fraud, premium rate evaluation mechanism and the business model. At last, the paper gives some reasonable suggestions to make the compulsory motor vehicle liability insurance act better.
\end{abstract}

Keywords: The third party liability compulsory insurance of motor vehicle, Insurance fraud, Deficit

\section{Introduction}

In the process of building an affluent society, car is changing from luxury consuming goods to ordinary merchandise, which causing frequently traffic accidents. To offering accident victims timely and effective medical treatment and reduce their financial burden, the law of "compulsory traffic accident liability insurance regulations" has come out in 2006. The compulsory insurance system came into effect in 2007.

However, the third party liability compulsory insurance of motor vehicle has continuously accumulated losses of 24 billion dollars as an insurance which has more than 80 years history in foreign countries. This huge loss has an important impact on many aspects of insurance companies, insurance agents and even insurance beneficiary. With such a serious loss, the key about how to find the reason of this problem and how to solve the problem is more and more important.

Actually, this problem has caused attention around insurance industry and most citizens. This paper helps to analyze reasons why the third party liability compulsory insurance of motor vehicle practicality comes up with this huge loss. The problem needs to be studied carefully. This paper analyzes the reasons and then provides some policy implications to improve the third party liability compulsory insurance of motor vehicle.

\section{Literature review}

The third party liability compulsory insurance of motor vehicle, with "no profit no loss" principle, has mandatory, commonweal and wide coverage to implement a policy of unified national insurance terms and basic rate. "No profit no loss" refers to the profit does not contain the rate of compulsory insurance. The nature of compulsory insurance is to ensure that the social security function is guaranteed, but its present situation is alarming.

In fact, as early as the beginning of the implementation, Zheng Lin and Yang Liu(2008) pointed out that the cross strong insurance business model and the "no profit no loss" principle are unreasonable and called for the improvement of the entity and procedure. (Shengwang M. 2013) After 4 years' loss, the domestic parties carried out 
a series of research on it. Guanru Li said, at present, business model of the third party liability compulsory insurance of motor vehicle is not clear, which leads to business difficulties. Changhe Gu and Jing Zhang (2011) also pointed out that the distorted and confusing insurance operation mode is the source of many problems. (Changhe Gu, Jing Zhang, 2011) In addition, the domestic scholars are still doing other researcher on the loss problem. Wenshuai Wang and Yanxia Li(2011) argues that the implementation of a unified national rate are obviously unfair because of big difference between different areas. (Wenshuai Wang, Yanxia Li, 2011) Li Xing(2011), from the disability evaluation mechanism and the court management point of view, proposed that the whole society should take the initiative to create a fair, reasonable judicial environment and should give more understanding and tolerance to this insurance. (Li Xing, 2011) Moreover, Yan Wu (2012) presents the scope of compensation should be limited to personal injury. "hit and run" shall have no compensation. (Yan Wu, 2012)

\section{Overview of the compulsory insurance system in motor vehicle of China}

In recent years, China's rapid economic and social development leading the rapid spread of motor vehicles. Due to a recent CASS survey, which shows that by 2012, the number China's automobile has reached 114 million, of which 17 cities have over one million cars. As the same time, the traffic cases also surged due to the increasing number of motor vehicles. In front of such a background, China's compulsory insurance system of motor vehicle has come out.

The third party liability compulsory insurance of motor vehicle has a significant meaning to accident concerned parties, relative insurance company, and the whole society. Firstly, the accident victim receive timely compensates, which is benefit to release the burden of perpetrators. Second, as a compulsory insurance, this kind of insurance has a high insurance density. Other insurance companies can find their potential customers and design certain insurance portfolio for different kind of customers, which can enhance financial strength of the company. Finally, the floating mechanical rate of fee can enhance drivers' safety awareness due to the reason that if they have no accident case this year, they can pay less next year.

The compulsory insurance relate with commercial insurance closely, which is the third party liability insurance that be forced to purchase by the state. But they differ from each other in many aspects. First, the compulsory insurance is public welfare insurance while common commercial insurance just for commercial purposes. Second, the compulsory insurance is mandatory while commercial insurance not. Third, the compulsory insurance covers almost all of the risk of road traffic accidents, and does not set deductibles, besides, it covers property loss while commercial insurance just offer personal injury compensations. Finally, compulsory insurance follow the principle of "no-fault" while commercial insurance follow the law of fault compensation.

\section{The causal analysis of the operating loss for Compulsory Traffic Insurance}

First, insurance fraud exists in our daily lives. The compulsory insurance and commercial insurance are operating simultaneously in the insurance market. Data show that commercial insurance loss ratio is generally about $50 \%$. The compulsory insurance is higher than commercial insurance in six years (Figure 1). By comparing with commercial insurance, the loss of compulsory is clearly depends on the amount of compensation. The more and more cases of insurance fraud have great impact on the insurance industry. So the problem of insurance fraud is one of the most important factors to affect the profit.

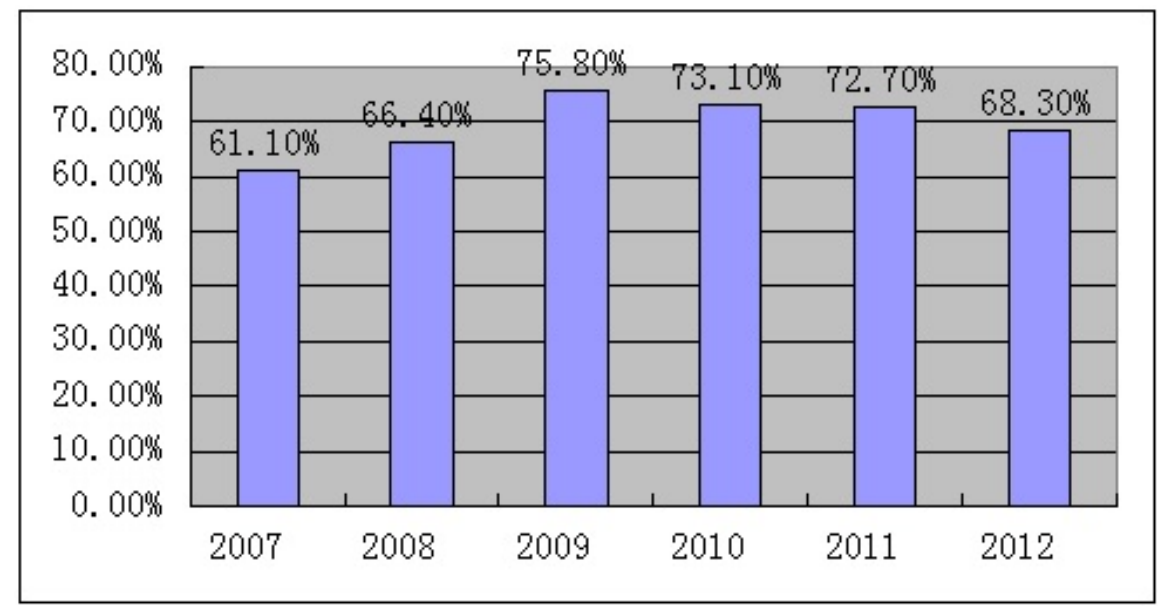

Figure 1. Loss Ratio of Compulsory Traffic Insurance(2007-2012)

Data sources: "motor vehicle traffic accident liability compulsory insurance business bulletin"(2007-2012) 
There are some fake accidents or providing false claims material behavior when it comes to the compulsory traffic insurance. There, more or less, exists this action in some factories. The amount is small, but over time, that starts to add up. There is "a single and multi-car accident" and replaced after the claims of fraud, the crime often cause a large loss amount. This kind of behavior often relates to internal staff's illegal behavior of the insurance company. There are the parties through the factory. What's more, there are many "insurance broker" and other "intermediaries" to contact to insurance companies' internal staffs. Then internal staffs help to buy insurance after the accident has happened in order to achieve the purpose of fraud. Even some insurance company staffs familiar with insurance claims procedures choose remote areas as the place where accidents happened. Through insurance in different places, they forged material fraud claims.

Secondly, premium rate evaluation mechanism needs to be improved. There are some differences in the premium rates and basic premium of commercial insurance in various areas. Income levels in different regions of China have their own characteristics, especially in eastern regions. Injury compensation standards, medical expenses and other costs are relatively high in these regions. But unified national rate of Compulsory Traffic Insurance is short of scientific bass. It's slightly rough in pricing actuarial pricing process. In fact, the insurance companies should assume unlimited liability and have independent pricing power.

Thirdly, compulsory traffic insurance has high operating costs. Data display [source: "China insurance Yearbook"] Serious losses are associated with higher operating costs. In 2011, except People Insurance Company, Ping An Insurance Company and Pacific Insurance Company, the ratio of operating expenses and premium income is kept below $30 \%$, other companies have very high ratio. Some companies, such as Zhongcheng car insurance, has ratio as high as $350 \%$. In addition, these two types of business operating costs are not independent in accounting. In addition, the compensation cost is increased because of differences between urban and rural areas. What's more, the cost of the tax is obviously overweight. It is seen from table 1, there are 27.2 billion of sales tax in 146.3 billion operating costs, which accounted for $19 \%$.

Table 1. Business Data of Compulsory Traffic Insurance (2007-2012)

Unit: USD

\begin{tabular}{ccccccccc}
\hline Year & $\begin{array}{c}\text { Premium } \\
\text { Income }\end{array}$ & $\begin{array}{c}\text { Compensat } \\
\text { ion }\end{array}$ & $\begin{array}{c}\text { Operating } \\
\text { Expenses }\end{array}$ & $\begin{array}{c}\text { Busine } \\
\text { ss Tax }\end{array}$ & $\begin{array}{c}\text { Scale of } \\
\text { Charges }\end{array}$ & $\begin{array}{c}\text { Under } \\
\text { writing } \\
\text { Profit }\end{array}$ & $\begin{array}{c}\text { Investment } \\
\text { Income }\end{array}$ & $\begin{array}{c}\text { Profits and } \\
\text { Losses }\end{array}$ \\
\hline 2007 & 75.63 & 29.98 & 23.54 & 4.15 & - & -4.77 & 3.7 & -1.07 \\
2008 & 55.34 & 37.08 & 17.73 & 3.05 & $31.7 \%$ & 1.03 & 0.73 & 1.76 \\
2009 & 66.79 & 47.2 & 18.6 & 3.7 & $29.9 \%$ & -5.3 & 2.4 & -2.9 \\
2010 & 84.05 & 62.1 & 26.8 & 4.6 & $28.4 \%$ & -9.7 & 2.5 & -7.2 \\
2011 & 98.26 & 74.9 & 27.7 & 5.5 & $28.2 \%$ & -11.2 & 2.0 & -9.2 \\
2012 & 111.43 & 82.1 & 32 & 6.2 & $28.1 \%$ & -8.3 & 2.9 & -5.4 \\
total & 491.5 & 333.36 & 146.37 & 27.2 & - & -38.24 & 14.23 & -24.01 \\
\hline
\end{tabular}

Data sources: "motor vehicle traffic accident liability compulsory insurance business bulletin", The China Insurance Regulatory Commission notice (2010) No. 17. \& (2009) No. 11

\section{Foreign insurance operation experience}

In America, only part of the states adopts the principle of liability without fault of Compulsory Traffic Insurance, but they are supporting the guarantee compensation system. Many states require legislation for driving people to prove their economic capacity. Economic compensation capacity is a prerequisite for automobile registration. In terms of standard rates, rates include factors of automobile price and the residence population density etc. At the same time, it's only link with the traffic accident, and has nothing to do with the violation of traffic rules. The insured can select appropriate insurance amount and pay the corresponding premium. In terms of the business mode, American carried out the operation mode of commercial market.

In Japan, blame custom is accepted. In addition, Japan carried out the principle of liability without fault and floating rate system. In terms of the business mode, The Japanese government acts as a leader and the insurance company is an agent. Insurance companies only charge a fixed charge fee and do not bear the risk of operation. The government also mitigates or reduces the business tax appropriately. In operation, premium and reparations charged by insurance 
companies are all transferred into public funds set up by government, and are allocated to each insurance company to have a balance of risks and payments according to a certain proportion.

In the international market, every compulsory insurance system has advantages. We can learn from American economic compensation ability guarantee system to improve the supporting system. We can follow the example of Japan, to continue to improve and promote the establishment of mandatory legislation guarantee, management, insurance company rescue fund assisted multi-level security system. At present, free rate is not allowed because of "no profit no loss" principle. But we can learn from the difference rate approach. In America and Japan, what's more, China, it also needs to increase the floating range and no claim bonus rewards and punishment strength to be fairer. At present, foreign insurance enterprises in China has allowed to underwriting this kind of insurance. Outstanding technology, management experience and management of insurance system of developed countries can be introduced into China market. We should make full use of this policy to promote the healthy development of insurance market.

\section{Policy implications}

The successful experience of foreign countries provides a new thinking for us. According to the new situation of China's compulsory insurance development, we need to adjust mainly from three aspects: the insurance fraud, the rate of accounting and business model. So we suggest that with the principle of mandatory, public welfare and broad coverage, and basing on the realities of China's insurance industry, we should solve the anti-insurance fraud problems, which helps to reduce business costs to make Compulsory Traffic Insurance better.

First, improve the ability of anti-insurance fraud. Various types of fraud in insurance company operating cost increased substantially. The insurance company economic loss is bound to be shifted on to our customers as increased premiums and other forms. So anti insurance fraud also requires the support of the consumers with solidarity and cooperation, closely communication between industries and cooperation collaboration, and the cooperation of insurance supervision department, the traffic control department, media supervision departments, consumer protection department. And the insurance company should be strengthened. At the background of auto focus platform being built, more efforts should be focused on promoting the construction of anti-insurance fraud platform, to speed up the popularization in the industry, then the insurance supervision committee and the traffic control department have shared information.

Fundamentally speaking, insurance fraud is a credibility problem. So we need to increase publicity efforts to improve the spiritual civilization. We also need to guide the consumers correctly from the industry supervision, policy advocacy and other multiple aspects. Insurance companies follow rules and consumers cooperate seriously. In addition, not only does credit management system should be improved, but also we should build perfect credit evaluation system. Turn social public condemnation to the economic punishment, so that the integrity obtain more trade opportunities and those people with bad faith must pay a heavy price, achieving a virtuous circle.

Second, rate accounting system should be improved. Personalized insurance rate should be determinate. We divide the different regional level according to the profit and loss status. High premium is in line with a high risk. Low premium is in accordance with low risk. In addition, according to the regional differences, we should set a floating reasonable interval. With the pilot experience in Jiangsu province, the regional differentiation rate reform could be promoted all over China. At the same time, we also need transparent rate accounting mechanism, and transparent complex process. It's a separate accounting management with the open approach that we need.

Market should play a decisive role to adjust the cost. The premium rate market competition mechanism could adjust the compulsory traffic insurance premium level. Moreover, with the data supported by traffic control department, we could determine the premium rate through actuarial investigation. In addition, because some insurance companies find their own company audits, and even have a cross between compulsory traffic insurance and other commercial insurance cost. Some insurance companies even put all costs into the compulsory insurance cost. Therefore, regulatory authorities should further ensure normative insurance business, conduct a special audit of compulsory traffic insurance, and let social public participate in the supervision of compulsory traffic insurance when necessary.

Third, scientific mode is accepted. To solve the deficit problem, we must solve the business model problem firstly. We can learn from international experience and consider agent model. In this mode, the insurance companies only need to charge a fixed charge fee. There is no risk of operation for insurance companies. At the same time, the government should reduce the business tax of compulsory traffic insurance to mobilize the enthusiasm of the insurance company. The western developed countries tend to give different levels of preferential taxation. According to statistics, USA, Canada and other 9 countries will impose insurance tax, including 6 state tax rate below 4\%, Britain and France, Germany, Denmark, Holland, and other 15 countries is free from the business taxes. But business 
taxes and surcharges account for 5.55\%-6\% in China. Therefore, we can reduce the business tax rate and the tax base or exempted from business tax with the reference of the agricultural insurance or export cargo insurance to improve the situation of loss.

\section{References}

Azzopardi M, Cortis D. (2013). Implementing Automotive Telematics for Insurance Covers of Fleets. Journal of technology management \& innovation, 2013, 8(4): 59-67.

Changhe Gu \& Jing Zhang. (2011). "Compulsory traffic insurance operation mode and principle of no profit no loss”, Journal of Northwest University for Nationalities(Philosophy and Social Science), 2011, 3: 019.

China insurance Yearbook. (2010). China insurance Yearbook.

Comparative study of compulsory motor vehicle liability insurance system. (2008). Chinese financial press.

Derrig R A, Tennyson S. (2011). The Impact of Rate Regulation on Claims: Evidence from Massachusetts Automobile Insurance. Risk Management and Insurance Review, 2011, 14(2): 173-199. http://dx.doi.org/10.1111/j.1540-6296.2011.01206.x

Dongmei C, Baige D. Mileage-Based Pricing in Vehicle Insurance Products: China as a case study.

Faure M, Bruggeman V. (2008). Catastrophic risks and first-party insurance. Conn. Ins. LJ, 2008, 15: 1.

Gönülal S O. (2009). Motor Third-Party Liability Insurance in Developing Countries: Raising Awareness and Improving Safety.

Guo-xue G, Shang-mei Z. (2013). Public liability of fire risk pricing model and empirical study based on compulsory insurance[C]//Management Science and Engineering (ICMSE), 2013 International Conference on. IEEE, 2013: 282-287.

Hofmann A. (2007). Internalizing externalities of loss prevention through insurance monopoly: an analysis of interdependent risks. The GENEVA Risk and Insurance Review, 2007, 32(1): 91-111. http://dx.doi.org/10.1007/s10713-007-0004-2

Li C S, Liu C C, Peng S C. (2013). Bundled automobile insurance coverage and accidents. Accident Analysis \& Prevention, 2013, 50: 64-72. http://dx.doi.org/10.1016/j.aap.2012.03.026

Li Xing. (2011). "Causes and Countermeasures of compulsory traffic insurance losses”, China Insurance, 2011 (7): pp. $28-30$.

Mengqin Xiao. (2011). "Problems and countermeasures of compulsory traffic insurance in the process of implementation", Shandong University.

Saito K, Kato T, Shimane T. (2007). Traffic Congestion and Accident Externality: A Japan-US Comparison. The BE Journal of Economic Analysis \& Policy, 2007, 10(1).

Shengwang M. (2013). Fairness of Compulsory Vehicle Liability Insurance Premium and Competition of Insurance Companies. Statistical Research, 2013, 8: 012.

Shengwang M. (2013). Fairness of Compulsory Vehicle Liability Insurance Premium and Competition of Insurance Companies. Statistical Research, 2013, 8: 012.

Wenshuai Wang \& Yanxia Li. (2011). "Loss puzzle of compulsory traffic insurance”, International Finance, 2011 (9): pp.119-120.

Yan Wu. (2012). "Perfection of compulsory insurance system”. Business Opportunities, 2012 (41): pp.24-24.

Zhang D, Wang B. (2012). Status Analysis of Farm Machinery Insurance and Orientation Research of Related Policies. Chinese Agricultural Mechanization, 2012, 1: 010.

Zhen Bi. (2011). "Cost study of compulsory traffic insurance”, China Insurance, 2011 (3): pp.44-46. 